\title{
Chapter 2 \\ The Epidemiology of HIV Among Sex Workers Around the World: Implications for Research, Programmes, and Policy
}

\author{
Nikita Viswasam, Justice Rivera, Carly Comins, Amrita Rao, \\ Carrie E. Lyons, and Stefan Baral
}

\section{Introduction}

The prevalence of HIV among sex workers is consistently high around the globe. The reasons for this high burden are complex, intersecting across lines of the behavioural, social, and structural realities experienced by sex workers of all genders. In this chapter, we build on systematic reviews of HIV among sex workers, as well as case studies rooted in the lived experience of sex workers and sex work organisations, to describe: (1) the global HIV burden among sex workers; (2) the factors and determinants that influence the HIV burden and risk; and (3) coverage of and gaps in interventions to reduce HIV-related inequities faced by sex workers over the past decade.

NV conceptualised the chapter, led the literature search, and drafted the sections on determinants of HIV, intervention coverage, research gaps; contributed to introduction, HIV burden, to literature review and overall editing of the chapter. $\mathrm{CC}$ contributed to the sections of intervention coverage, determinants of HIV, to conceptualisation of the chapter, the literature review, and to overall editing of the chapter. AR drafted the HIV global burden section, contributed to conceptualisation of the chapter, literature review, and overall editing of the chapter. CEL contributed to the structural determinants section and overall editing of the chapter. As community co-author, JR drafted community case studies featured in the introduction, drug use, determinants of HIV section and contributed to overall editing of the chapter. SDB contributed to conceptualisation of the chapter, conclusion, and overall editing of the chapter.

N. Viswasam $(\varangle) \cdot$ C. Comins $\cdot$ A. Rao $\cdot$ C. E. Lyons $\cdot$ S. Baral Center for Public Health and Human Rights, Department of Epidemiology, Johns Hopkins Bloomberg School of Public Health, Baltimore, MD, USA

e-mail: nviswas@outlook.com; ccomins1@jhu.edu; arao24@jhu.edu; clyons8@jhmi.edu; sbaral@jhu.edu

J. Rivera

Reframe Health and Justice, Baltimore, MD, USA

Sex Workers Outreach Project (SWOP), Washington, DC, USA

e-mail: justice@reframehealthandjustice.com 


\section{Epidemiological Data on the Global Burden of HIV Among Sex Workers}

Despite overall reported progress towards the ambitious 90-90-90 targets in the general population, robust evidence continues to indicate severe unmet global need for HIV prevention, treatment, and care services among sex workers. As of 2019, sex workers continue to face a disproportionately high burden of HIV compared to other adults of reproductive age. A systematic review and meta-analysis by Shannon and colleagues published in 2018 found that cisgender women sex workers globally experience an HIV prevalence of 10.4\% (95\% Confidence Interval (CI): 9.5-11.5), with the highest regional HIV prevalence estimates reported in Eastern and Southern Africa (33.3\% ; CI: 29.2-37.6), followed by West and Central Africa (20.1\%, CI: 16.7-23.8) [1]. As Shannon et al. report, this prevalence remains unacceptably high and is largely unchanged from data reported in 2014 [1]. Although there has been some progress, access to services and information is uneven across populations and hampered by social and structural barriers [1].

Following Shannon et al.'s meta-analysis reporting data from 2006 to 2017, 19 additional studies on HIV prevalence were published in 2018, primarily among cisgender women sex workers (Table 2.1). These prevalence data indicate overall patterns of HIV acquisition among female sex workers across regions that were similar to those noted in the previous reviews. We see the highest prevalence in Southern Africa: one study in Soweto, South Africa documented a prevalence of 53.6\% (95\% CI: 47.5-59.9) among 508 sex workers recruited through respondent-driven sampling (RDS) [21]. Another study of 2617 sex workers in 14 communities across Zimbabwe reported a prevalence of $59 \%$ overall, and saw a significantly lower burden among younger, compared to older, women sex workers (35\% vs. 67\%) [22]. Additional studies in other regions documented burdens similar to the estimated regional prevalence in Table 2.1-with $28 \%$ in Tanzania [23] and 31.4\% in Uganda from the Eastern Africa region [24]; 11.5\% in Togo from West Africa [2], in South America-Brazil: 5.3\% [3, 4].

These results largely confirm those presented by Shannon and colleagues - that overall, the burden of HIV among cisgender women sex workers remains unchanged from what it was over a decade ago.

Differences in HIV prevalence among sex workers across regions partly reflect estimates of HIV prevalence among the general adult population in different regions. The Joint United Nations Programme on HIV/AIDS (UNAIDS) estimates that 70\% of people living with HIV globally live in sub-Saharan Africa [1, 5]. Furthermore, in different regions, varying levels of poverty, education, HIV-related stigma, access to health care, and human rights violations including discrimination and violence, all affect uptake of HIV testing, awareness of status, and retention in care and treatment for those living with HIV-which limits the impact of treatment as prevention among sex workers $[5,6]$.

Data on cisgender men and transgender women and men sex workers, while growing, remain inadequate, especially as these data are often only available as 
2 The Epidemiology of HIV Among Sex Workers Around the World: Implications...

Table 2.1 HIV prevalence among sex workers reported in studies published in 2018

\begin{tabular}{l|l|l|l}
\hline $\begin{array}{l}\text { World } \\
\text { region }\end{array}$ & $\begin{array}{l}\text { Reported HIV prevalence } \\
(\%)\end{array}$ & $\begin{array}{l}\text { Sex worker } \\
\text { population }\end{array}$ & First author, year, citation \\
\hline Asia and Pacific & \multicolumn{3}{|l}{} \\
\hline China & 6.8 & Cisgender women & Dong et al. (2018) [2] \\
\hline & $0.92-3.21$ & Cisgender women & Lai et al. (2018) [3] \\
\hline & 2.74 & Cisgender women & Zhu et al. (2018) [4] \\
\hline Thailand & 8.8 & Transgender women & Seekaew et al. (2018) [5] \\
\hline & 11 & Cisgender men & Goldsamt et al. (2018) [6]
\end{tabular}

Eastern Europe and Central Asia

\begin{tabular}{l|l|l|l|} 
Ukraine & 6.3 & Cisgender women & Dumchev et al. (2018) [7]
\end{tabular}

Middle East and North Africa

\begin{tabular}{l|l|l|l}
\hline Morocco & 11 & Cisgender women & Kouyoumjian et al. (2018) [8]
\end{tabular}

Eastern and Southern Africa

\begin{tabular}{l|l|l|l}
\hline Kenya & 5.6 & Cisgender women & Becker et al. (2018) [9] \\
\hline Nigeria & 25 & Cisgender women & $\begin{array}{l}\text { Awofala and Ogundele (2018) } \\
{[10]}\end{array}$ \\
\hline Malawi & 62 & Cisgender women & Herce et al. (2018) [11] \\
\hline Angola & 8 & Cisgender women & Herce et al. (2018) [11] \\
\hline Tanzania & 28 & Cisgender women & Vu and Misra (2018) [12] \\
\hline Uganda & 31.4 & Cisgender women & Doshi et al. (2018) [13] \\
\hline Zimbabwe & 59 & Cisgender women & Napierala et al. (2018) [14] \\
\hline
\end{tabular}

West and Central Africa

\begin{tabular}{l|l|l|l}
\hline Benin & 41 & Cisgender women & Diabate et al. (2018) [15] \\
\hline Latin America and Caribbean & \multicolumn{2}{l}{} \\
\hline Brazil & 5.3 & Cisgender women & Szwarcwald et al. (2018) [16] \\
\hline & 5.3 & Cisgender women & $\begin{array}{l}\text { Ferreira-Junior et al. (2018) } \\
{[17]}\end{array}$ \\
\hline Peru & 3 & Cisgender men & Degtyar et al. (2018) [18] \\
\hline & 19 & Transgender women & Degtyar et al. (2018) [18]
\end{tabular}

Western and Central Europe, North America

\begin{tabular}{l|l|l|l}
\hline Europe & 6.38 & Cisgender men & $\begin{array}{l}\text { Fernandez-Lopez et al. (2018) } \\
{[19]}\end{array}$ \\
\hline Portugal & 14.9 & Transgender women & Gama et al. (2018) [20]
\end{tabular}

sub-samples of cisgender men who have sex with men and transgender women. As part of a larger published work on transgender sex workers [7], Scheim and colleagues built on earlier reviews [21, 22] with a 2018 global review of HIV prevalence data among transgender sex workers. This review identified studies undertaken between 2008 and 2015, reporting prevalence estimates ranging 17-34\% in majority-sex worker samples of transgender women, primarily in Asia and Latin America [10]. In Brazil, survey data stratified by lifetime sex work status found that transgender women sex workers had an HIV prevalence of 39\%, compared to $19 \%$ of transgender women who did not report sex work [23]. A 2015 review of HIV among cisgender men sex workers found that approximately a third of the 52 countries that 
reported HIV prevalence data on men sex workers to the United Nations General Assembly reported an HIV prevalence of $12.5 \%$ or higher, noting that HIV burdens among men sex workers were consistently higher than in men in general [24]. Overall, more comprehensive HIV data are needed for cisgender men sex workers and transgender sex workers.

\section{Engagement in Care and the HIV Treatment Cascade}

The HIV treatment cascade begins with testing for HIV and, if diagnosed, linkage to HIV health services, initiating HIV antiretroviral therapy (ART) — and, in the absence of primary and secondary resistance to ART, staying on HIV treatment to remain on the path to viral suppression. Recent data demonstrate that there is no risk of onward HIV transmission when people have achieved viral suppression. Since 2010, multiple reviews have summarised available quantitative data on sex workers' engagement in HIV care and treatment [25-27]. These reviews, and updated data from studies published in 2018, reveal that 12 countries in total had data collected between 2011 and 2016 on cisgender women sex workers [28-35, 43]. One in Indonesia also contained data on transgender persons, though they did not report data for the subgroup of transgender sex workers [36].

Among sex workers aware of their HIV diagnosis, reports of being currently on treatment ranged from $33 \%$ in Burkina Faso and Togo to $84.4 \%$ in Papua New Guinea [37]. Viral suppression, where data were available, ranged from $23 \%$ in Indonesia and Cambodia to $77.8 \%$ in Zimbabwe [38]. While comparing cascade data is challenging because of the different definitions used to measure each cascade step across studies, ${ }^{1}$ combined analyses in 2014 assessed ART uptake and adherence among cisgender women sex workers globally [39]. Pooled estimates found that about 38\% (95\% CI: 29-48) of sex workers living with HIV were currently on treatment, about 76\% (95\% CI: 68-83) were adherent, ${ }^{2}$ and 57\% (95\% CI: 46-68) were virally suppressed [39]. While reported adherence levels were similar to women in the overall population [39], less than half of sex workers living with HIV were estimated to be on treatment, and two-thirds of them were virally suppressed.

Various studies have documented barriers throughout engagement in care and treatment, including intersecting stigmas, inadequate food, and substance use [40].

\footnotetext{
${ }^{1}$ Authors of the Mountain et al. analyses used the following definitions for the HIV treatment cascade: ART uptake was defined as the fraction of all HIV-infected individuals or the fraction of all ART-eligible individuals who either initiated ART in a specified follow-up period, currently use ART, or ever used ART. ART attrition: the fraction using ART who were either lost-to-follow-up, died or discontinued ART, or the fraction of treatment-experienced individuals no longer on ART. ART adherence: the fraction achieving a pre-defined threshold of adherence (e.g. $\geq 90 \%$, $\geq 95 \%, 100 \%$ ). Viral suppression: fraction with undetectable plasma viral load following ART initiation.

${ }^{2}$ ART adherence was defined by Mountain et al. as the fraction achieving a pre-defined threshold of adherence, e.g. $\geq 90 \%, \geq 95 \%, 100 \%$, which were available from nine studies.
} 
Recent results have shown even larger gaps in care engagement among younger sex workers. In Zimbabwe, for example, a study comparing sex workers between the ages of 18 and 24 to those aged 25 or older found that younger women diagnosed with HIV were less likely to be previously aware of their status, to report being on treatment, and to be virally suppressed [41]. While HIV testing rates among sex workers has increased with knowledge of HIV, there are still documented gaps among sex workers in beginning voluntary HIV treatment, with those receiving continued support being more likely to stay on treatment and becoming virally suppressed.

\section{Determinants of HIV Among Sex Workers}

Broadly, structural determinants of HIV describe higher level, contextual factors that influence individual risks of HIV. Known structural determinants of HIV in the context of sex work include stigma, violence, criminalisation, and policing practices. Injecting and non-injecting drug use, also linked to structural determinants, play additional roles in HIV acquisition among sex workers.

\section{Stigma}

Stigma is a process by which an individual is labelled based on characteristics that may not adhere to socially accepted norms, resulting in reduced well-being and opportunities for that individual. Sex workers may experience stigma due to their engagement in sex work, HIV status, or other identities and behaviours (e.g. drug use, gender identity, sexual orientation, migration status) as well as the intersections of these characteristics. HIV-related stigma could be based on actual or perceived status of living with HIV. This can lead to fear or avoidance of health services (anticipated stigma) because they associate engaging in care with having experienced discrimination (enacted stigma) at the hands of healthcare providers. Mistreatment by healthcare providers may also affect the quality of care provided to sex workers. Perceived, anticipated, and enacted stigmas are major barriers to HIV prevention, testing, and care for all sex workers, which can also be exacerbated by multiple or intersecting stigmas [46, 47].

Identities are often multiple and intersecting, and therefore sex workers may overlap with other key populations, including people who use drugs and those with non-heteronormative sexual orientations and gender identities. The intersectional stigmas faced by more marginalised subgroups of sex workers are a powerful determinant of HIV, warranting further research attention. In Zimbabwe, nine out of ten sex workers reported experiencing stigma due to sex work. Those who reported experiencing stigma due to sex work also reported experiencing more HIV-related stigma than those who did not [42]. In Guatemala, MSM sex workers reported 
higher levels of discrimination than MSM non-sex workers, and transgender sex workers reported significantly higher proportions of discrimination compared to both MSM sex workers and MSM non-sex workers, suggesting intersecting stigmas due to both gender identity and sex work [49].

Interventions addressing stigma in the context of sex work are therefore critical for addressing the HIV burden faced by sex workers. A community intervention for female sex workers and healthcare providers in Senegal observed that teaching strategies for addressing stigma and discrimination reduced sex workers' fear of seeking health services and inclination to avoid health services [50]. This speaks to the need for sex work programmes to address stigma in combination with other factors to improve HIV prevention and care.

\section{Criminalisation, Violence, and Policing}

National policy-making around sex work has predominantly relied on criminal laws and legal frameworks, whether through criminalisation, containment, regulation, or eradication $[6,51]$. In many settings that criminalise sex work, police arrest and harassment have often displaced sex workers and driven them into isolated working locations, disrupting support networks, service delivery, and opportunities for risk reduction [52]. This results in increased risk of physical and sexual violence and higher odds of HIV/STIs [52]. Furthermore, as the case studies in this chapter illustrate, sex work criminalisation has also led to the exacerbation of inequalities experienced by transgender persons, migrants, and sex workers who use drugs.

On the basis of human rights and health evidence, Amnesty International called for the full decriminalisation of sex work in 2014 and its separation from the definition of sex trafficking [53]. Decriminalisation of sex work refers to the absence of laws that criminalise selling sex, buying sex, the organisation of and facilitation of sex work [53], as well as the absence of other legal oppression [54]. Shannon and colleagues highlighted the potential HIV infections averted through decriminalisation's downstream effects on work environment, violence, and risk behaviours [55]. European countries which have partially legalised aspects of sex work displayed a lower HIV prevalence compared to those with full criminalisation [56]. Across subSaharan African countries, the odds of HIV among cisgender women sex workers in criminalised and non-protective settings was higher than in settings in which sex work is partially legalised. Furthermore, the effect of stigmas on HIV was higher in criminalised and non-protective settings compared to partially legalised settings [57]. However, partial legalisation policies in Sweden, Norway, and the UK, where clients of sex work and/or third-party managers are criminalised while the selling of sex is legal, have also been associated with many of the same HIV risks as full criminalisation, reinforcing the need for full decriminalisation to optimise health outcomes [58]. European countries with partial legalisation were shown to have higher HIV prevalence compared to the sole European country where buying, selling, and managing of sex work was legalised-Germany [25]. Ultimately, a larger 
sample size of countries with decriminalisation is needed to fully demonstrate quantitative differences in health outcomes by legislative model.

On a global level, individuals who undertake sex work are deeply affected by verbal, physical, and sexual violence perpetrated by clients, police, intimate partners, and others throughout their lifetime, both before their entry into sex work and during sex work $[20,59]$. Violence increases their vulnerability to HIV, especially in cases of sexual violence. It also influences sexual risk behaviours, as well as one's access to prevention and care. Experiences of physical and sexual violence through a sex worker's lifetime are strongly associated with higher odds of unprotected sex and of acquiring HIV [3, 59-61].

Given the observed association between criminalisation of sex work and health outcomes, a recent systematic review and combined analyses undertaken by Platt and colleagues assessed 20 quantitative studies looking at the effect of sex work laws on health [52]. Repressive policing was linked to higher odds of experiencing physical or sexual violence by clients, intimate partners, police, or other parties. It was also related to higher odds of unprotected sex and twice the odds of living with HIV/STIs. It is particularly linked to the confiscation of needles/syringes, another factor increasing HIV risk [52]. Footer et al.'s systematic review of policing practices also found that experiencing sexual coercion, extortion, and arrest were each consistently associated with HIV or STI infection across studies, highlighting the role that policing, enabled by criminalisation, plays in HIV vulnerabilities [62]. The case study below illustrates some of these experiences.

\section{Case Study 1 Sex Work, Violence, and HIV in Asia}

Sex workers of all genders experience high rates of institutional, community-level, and interpersonal violence that negatively impact their physical, sexual, and mental health. A multi-country qualitative study by the United Nations Development Programme, United Nations Populations Fund, and Asia-Pacific Network of Sex Workers (2015) highlights gender-based violence as an important 'push' factor into sex work.

While at work, police violence-including raids and sexual extortion-increase the vulnerability of sex workers to client and community perpetrated violence as well as to HIV and STIs. Some workers contract STIs from sexual assaults, and others sacrifice condom use in exchange for immediate safety from police or client violence. An account of a female sex worker in Myanmar describes this.

We had to do without one [a condom] because we couldn't go out late at nights to buy condoms if there was a police project [raid or crackdown]. Sometimes, I have many clients on that night and it's kind of urgent and didn't have time to find condoms. So I had to stay (to provide sexual services) with them without condoms (Female participant in Yangon). [26]

Frequently, sex workers who survive police and client violence do not report it, fearing that this may result in more violence towards themselves. They may also fear violence from healthcare settings and neighborhoods, especially where HIV infection is either actual or perceived. In addition to this institutional violence, most sex workers in the study reported experiencing intimate partner violence. 
This case study further found that ciswomen sex workers were more likely to experience sexual violence related to a perception that they were challenging traditional gender roles. Transgender and cismen sex workers were more likely to experience physical violence related to challenging masculinity and heterosexual norms. Intervention outcomes that can reduce violence against sex workers include safe working environments, education on rights and safety, collectivisation, and access to stigma-free health care.

This data, along with qualitative work from New Zealand and New South Wales, Australia, where sex work is decriminalised, further demonstrates the need for full decriminalisation towards achieving better sex worker health and well-being [63, 64]. In Senegal, sex work is legalised but regulated through policies that mandate registration of sex workers and compliance to monthly health checks. A 2018 study noted both positive and negative effects of Senegal's sex work registration [65]. Overall, registered sex workers had higher average earnings due to more sex work activity, higher linkage to health services and lower STI prevalence. They had lower reported well-being, however, due to the still-prevalent social stigma associated with the disclosure of sex work status that came with registration. This reinforces Amnesty International's stance that any regulation of sex work should respect the agency of sex workers $[53,65]$. Building on the efforts of sex worker movements and advocacy organisations as well as existing data, we reiterate the statements of Shannon and colleagues: the literature increasingly calls for full decriminalisation along with legal protections from exploitation and offers guidance on policy directions emphasising the health and human rights of sex workers [1, 51].

\section{Migration}

Migration, occurring between or within countries, is prevalent among sex workers, due to drivers such as economic needs, armed conflict, family separation, and a desire for social mobility or enhanced economic opportunities. Migration may influence HIV risk through sexual behaviours, economic vulnerability, and social capital through networks, as well as access to prevention and treatment services. Migration has been linked to a higher STI burden, likelihood of unprotected sex along with barriers to HIV care across settings, and to HIV acquisition in some settings [21, 66], though not all [67]. Migration status also interacts with other factors that can amplify the vulnerability of sex workers, as seen with undocumented sex workers in Europe in the case study below [68]. Overall, however, data suggest that migration has a complex relationship with health outcomes, with factors dependent on individual and local contexts [69-71]. 


\section{Case Study 2 Migration and Mobility, TAMPEP International Foundation, 2009 and International Committee on the Rights of Sex Workers in Europe, 2016}

In most European countries, residency permits and health insurance are bound to a person's employment. Sex workers living and working in countries that do not recognise sex work as work are structurally excluded from the public health system. Even where insurance is extended or health care is available, efforts to reach cultural minorities fall short in the absence of language translation services or availability of printed materials in multiple languages. Additionally, lack of protection from deportation reinforces migrant sex workers' fears of expulsion or residence restrictions. Lack of access to health care is compounded by stigma, racism, and sexism faced by many when attempting to access preventative services and treatment.

When looking at the case of undocumented sex workers, many of these factors converge to make them particularly vulnerable to HIV with less access to care, where "[r]epressive laws governing sex work paired with anti-immigration policies push many migrant sex workers into irregular migration situations which highly affects the range of health services available to them in their respective host country. The scope of health services granted to migrants in irregular situations is defined by national legislations (Surveilled. Exploited. Deported., 2016)."

In sum, strong evidence indicates the key role of structural factors in rendering sex workers particularly vulnerable to health inequities. For those living with HIV, overlapping structural factors often act as a barrier to accessing and being retained in care for sex workers. There remains a need for evidence-based structural interventions taking a multi-pronged approach, seeking to address healthcare provider discrimination, police repression, stigma, and experiences of violence to reduce the burden of HIV and barriers to HIV care.

\section{Drug Use Among Sex Workers}

\section{Case Study 3 Sex Workers Who Use Drugs in Seattle, Washington, USA: Reframe Health and Justice, 2018}

The prominent outdoor sex work market in Seattle is near the outskirts of the city, far away from where social services are concentrated downtown. Only one harm reduction agency exists along its track, and though Seattle harm reduction programmes provide medicated assisted therapy (MAT) or MAT referrals, this particular location is only open for a handful of hours each day, 4 days a week. Seattle is among the few US cities that prioritise an 'end-demand' ${ }^{3}$ [72] approach to sex work, which has resulted in inconsistent diversion from arrest, expansion of

\footnotetext{
${ }^{3}$ End-demand is defined by the Global Network of Sex Work Projects (NSWP) as a legislative model that criminalises the purchase of sex work, while not criminalising the selling of sex work (NSWP, 2014).
} 
anti-prostitution-oriented services, and decreases in clientele. The combination of a harsh sociopolitical environment and lack of services creates a perfect storm for an HIV outbreak, which occurred among street-based sex workers who inject drugs in this area just months after the passage of a 2018 federal US law restricting the availability of online advertising venues, thereby decreasing market prices and sex workers' ability to survive.

Sex workers in this area report experiencing high levels of overdose, as well as structural and interpersonal violence. They often must make a decision between having unprotected sex or experiencing withdrawal, sleeping on the street, or refusing a meal to their children. Some of these women, both cis and trans, know about the availability of Pre-exposure prophylaxis (PrEP), but cannot make it downtown during service hours because they must work and make money. Others do not have money for transportation or cannot find anywhere to store their belongings during the appointment. The lack of affordable housing, unavailability of hepatitis $\mathrm{C}$ treatment, and de-prioritisation of syringe service programmes across the state also negatively affect behavioural factors specific to this population, including high rates of stimulant use.

The overlap of sex work and drug use has been increasingly documented. The case study above illustrates the complex challenges facing sex workers who use drugs, including an elevated burden of HIV across diverse contexts, including Asia, Europe, and North America. Evidence has linked enhanced health-related harms among people who use drugs to structural factors-poor access to harm reduction and evidence-based drug treatment, criminalisation and repressive policing practices, stigma, and discrimination - as well as to individual factors, such as a higher risk of HIV transmission resulting from impaired decision-making in the context of sexual and drug use practices (e.g. unprotected sex, sharing of injecting equipment). Reported current drug use among sex workers, including the use of crack, ecstasy, cocaine, and injectable drugs including heroin, has been associated with 2-6 times the odds of HIV infection, compared to those reporting no drug use or former drug use $[3,73]$.

Cisgender African American women who reported trading sex for drugs alone had higher burdens of HIV than those who reported selling or trading sex for economic resources and drugs [74]. In Vietnam, $10 \%$ of sex workers sampled across ten provinces reported ever using drugs. In every province surveyed, sex workers who injected drugs had a higher HIV prevalence compared to those who did not, considering that parenteral transmission (through sharing injecting equipment) comes with a higher risk of HIV infection compared to sexual transmission [75]. The overlap of sex work and injecting drug use has also been linked to a higher likelihood of both drug-related and sexual risk behaviours, including sharing injection equipment and unprotected sex [73, 76, 77].

While studies directly linking drug use and HIV among transgender sex workers are limited, a New York area study of such sex workers found that a relationship between sex work and incident HIV/STI was significantly explained by interrelated 
effects of drug use, gender-related abuse, ${ }^{4}$ and depression [78]. This highlights the interplay of social and structural determinants driving substance use and subsequent HIV outcomes among sex workers [78].

Repressive police practices play a key role in heightening HIV risk among sex workers who use drugs [52]. Abusive police practices—such as confiscating safe drug use supplies (obtained from harm reduction programmes) as well as condoms (considered evidence of sex work) — decrease the ability of sex workers who use drugs to practise safe drug use and safe sex. The experiences of sex workers in Seattle described at the opening of this section highlights this, and their personal statements, in particular, capture how police attitudes affect sex workers' ability to protect themselves against sexual and drug-related HIV risks:

'They are scared of them for some reason. They treat them like they are an uncapped needle when they aren't even open.' 'I had more than 3 condoms and was told that this meant that I was a hoe and could be arrested.' '[The police] used to take condoms and poke holes in them and still take me to jail. Said that condoms can be used as evidence of prostitution.' [27]

\section{Coverage of Interventions Addressing HIV Burden}

\section{Community Empowerment Responses}

While there have been many sex worker peer-based education programmes for HIV prevention, the past decade has also seen a growing emphasis on human rightsaffirming community mobilisation approaches to improving health outcomes among sex workers $[79,80]$. These approaches recognise the economic and structural determinants affecting sex worker well-being. They depend on processes of empowerment and grassroots initiatives born from a collective identity in sex worker communities [81, 82].

For HIV prevention and care, this means local sex worker communities are part of the process of determining the needs of sex workers, identifying their specific barriers to engaging in HIV prevention and care, and leading the implementation of programmes designed to address these needs. Kerrigan and colleagues conducted a systematic review and meta-analysis of community empowerment responses to HIV among sex workers in low- and middle-income settings. They found that the combined effect of community empowerment approaches led to lower odds of gonorrhea, chlamydia, and syphilis, a 32\% decrease in odds of HIV infection, and triple the odds of protected sex with clients, as previously described in the 2018 Lancet update $[1,79]$.

\footnotetext{
${ }^{4}$ Nuttbrock and colleagues defined measurement of "gender abuse" among study participants as reported experiences of verbal abuse and/or physical abuse during the previous 6 months that participants attributed to their gender identity or presentation [78].
} 
In India, the Sonagachi project and Avahan initiative involved multiple community-based approaches, including provision of peer outreach, behaviour change communication, clinical prevention, and management services for STIs [81, 83-86]. This initiative also involved community mobilisation and structural interventions including formation of violence response teams, police sensitisation, journalist and legal training to peers, and establishment of community advisory committees who were given leadership and organisational development training [86].

A round of surveys indicated that women with high exposure to community mobilisation activities were more likely to have accessed HIV/STI services, to report having protected sex with a client during their last sexual encounter, and less likely to be infected with chlamydia or gonorrhea compared to women with low exposure [81].

In districts with Avahan programmes, 11,000 sex workers completed surveys and testing for HIV in 2005-2006, as did another 11,000 sex workers in 2008-2009. Stronger declines in HIV prevalence were seen in districts with larger increases in programme coverage between 2006 and 2008, though measures of mortality and HIV incidence, which can also contribute to an observed decline in HIV prevalence, were not reported [85].

Abriendo Puertas (Opening Doors) in the Dominican Republic and Encontros in Brazil provided combination structural and clinical STI/HIV prevention interventions to sex workers [87-89]. These included expanded clinic hours, sensitisation training of care providers to create a supportive and enabling environment for sex workers, individual- and community-level activities which included peer education, counselling, workshops, and social activities building relationships and dialogue among sex workers to promote social cohesion. Ten months into Abriendo Puertas, a survey of sex workers found that having taken part in the intervention resulted in higher odds of protected sex and of reported adherence to ART in the last 4 days, from the time of the survey [87]. Participants also reported lower rates of drug and alcohol use before sex and more engagement in care although viral load and level of retention in care did not change. Additionally, participants who reported higher social cohesion (feeling trust and mutual aid within the sex work community) had lower odds of having an STI [88]. Encontros programme participants had a higher odds of having protected sex with regular clients, and a non-significant two times lower odds of incident STI, compared to those who did not participate in the programme [89].

Overall, there exists only a handful of community empowerment interventions with documented effects on HIV outcomes, and these come with limited scale-up, demonstrating a need for greater adaptation and expansion of programmes. Wirtz and colleagues modelled the impact of expanding community empowerment interventions to $65-75 \%$ national coverage in the epidemic contexts of Kenya, Brazil, Thailand, and Ukraine [90]. They modelled two scenarios: one was a combination of empowerment interventions and universal ART expansion implemented on a national scale, and the other was the implementation of community empowerment interventions alone. The expansion of empowerment interventions was estimated to 
reduce new infections between $8 \%$ and $12 \%$ among sex workers across the four countries, and, combined with universal ART expansion, reduce new infections between $17 \%$ and $33 \%$ among sex workers across the four countries. These results paired with the above case studies demonstrate the powerful role community empowerment responses can play in addressing the burden of HIV among sex workers around the world.

\section{Influence of Access to and Uptake of Biomedical HIV Prevention Tools on the Epidemiology of HIV}

In response to growing calls for tailored combination HIV prevention among sex workers $[1,91]$, the epidemiology of HIV in sex work is also shaped by scale-up of traditional and emerging biomedical interventions such as HIV self-testing (HIVST), PrEP, sexual and reproductive health service integration with HIV, and vaginal and rectal microbicides. Though studies have documented promising feasibility and acceptability of many of these emerging biomedical interventions among sex workers, implementation challenges still exist, and further community engagement is needed to inform ethical and sustainable implementation and scale-up. Challenges described in the epidemiological literature include negative perceptions of PrEP and other tools at the community-, peer-, and individual-levels, clinical side effects, and experiences of violence and coercive testing that undermine acceptability, utilisation, and retention efforts [92-96].

\section{HIV Self-Testing (HIVST)}

Integration of voluntary access to HIVST within comprehensive HIV prevention services among sex workers can support the World Health Organization's (WHO) recommendation of frequent HIV testing for early HIV diagnosis and reduction in HIV acquisition [97]. In two HIVST randomised controlled trials implemented in Uganda [28] and Zambia [29], HIVST was considered acceptable among sex workers, achieved adequate HIV testing coverage, and was preferable to and substituted for facility-based HIV testing services [100].

As national and regional health programmes aim to reach $90 \%$ testing coverage of the 90-90-90 HIV care cascade targets (90\% testing, $90 \%$ treatment, $90 \%$ viral suppression among people who live with HIV), HIVST may present an opportunity to address suboptimal HIV testing rates and the low proportion of sex workers who know their status. However, HIVST also comes with limitations and challenges.

Linkage to care among those testing positive in Zambia was lower in HIVST arms when compared to standard of care, illustrating that HIVST may not 
substantially improve gaps across the HIV care cascade, especially in contexts where HIV testing and linkage to care are already high [99].

A randomised controlled trial among ciswomen sex workers and men truck drivers in Kenya found that, while most participants who tested within the intervention arm chose the HIVST option, the cost to offering HIVST was double that of routine facility-based HIV testing, largely driven by the high price of test kits [101]. More efforts must be made to improve linkage to care following HIVST and reduce testing costs to improve the community-level effectiveness of HIVST among sex workers.

\section{Pre-exposure Prophylaxis (PrEP)}

Sex workers have shown high interest in oral PrEP [100] as a prevention strategy for HIV. PrEP has been shown to reduce HIV acquisition among heterosexual women by up to $79 \%$ in clinical trials, and up to $85 \%$ in those with detectable drug levels [102]. Furthermore, PrEP among sex workers in South Africa had an estimated service delivery cost of $\$ 136$ per person-year, compared to $\$ 406$ for early ART per person-year, demonstrating cost-effectiveness [103].

Clinical trial data, along with real-world implementation data collected among men who have sex with men [104, 105], have informed the WHO's guidelines to offer PrEP as part of a comprehensive HIV prevention package in HIV high-burden settings [106]. The success of PrEP as an HIV prevention tool depends on adherence. Modelling insights highlight that PrEP adherence by sex workers can achieve a level of effectiveness exceeding that of condoms, noting that PrEP will benefit reduction in HIV acquisition, even if condom use is reduced [107]. However, outside of status-disclosed, sero-discordant partnerships (where only one partner lives with HIV), sustained PrEP use by ciswomen sex workers and adult women overall has been limited, in both clinical trial and real-world settings [102, 108-111]. PrEP demonstration projects among sex workers, adolescent girls, and young women in South Africa [103, 112] and among the general population in Kenya [110], have shown that the proportion of PrEP maintenance is cut in half by 1-month after initiation and continues to decline during the first 6 months before stabilising [92, 112]. The Zimbabwe SAPPH-IRe study had an average PrEP retention period of 4 months among ciswomen sex workers enrolled [111], and obstacles to PrEP among sex workers have included provider- [103, 113], community- [114], and individuallevel barriers [113-120]. Limited healthcare provider knowledge, communication, and support for PrEP for sex workers [113, 121] — as well as client-level concerns over side effects, PrEP-related stigma, awareness, and social pressure from partners and peers-have inhibited PrEP use [113, 115]. However, more research specific to sex workers is needed to identify and address limitations in the delivery of PrEP which prevent sex workers from continuing its sustained use. Modelling suggests that the uptake of HIV prevention products like PrEP could result in a decrease in the use of condoms in sex work due to a perceived reduction in the utility of condoms 
for HIV prevention though PrEP use alone does not prevent unintended pregnancy or STIs [119]. This reinforces the need for HIV prevention programming to be part of a health service package for sex workers which emphasises provision of STI screening and treatment services, reproductive health services offering contraception, and condom supply along with PrEP availability, to maintain their sexual and reproductive health.

\section{Other Innovations}

With growing recognition that pregnancy is common among ciswomen sex workers and the majority have at least one child [30-33], there is increasing awareness of the need to integrate sexual and reproductive health (SRH) services into sex workers' comprehensive HIV prevention service package [125, 126]. Yet access to a combined SRH service and HIV prevention innovation can be undermined by individual, social, and structural determinants, a dynamic exacerbated among sex workers in conflict-affected settings [127]. Generally, economic evidence on integrated HIV and SRH interventions among sex workers is limited, but, where available, integrated services are shown to be highly cost-effective [128].

For other innovative biomedical HIV prevention tools, such as oral PrEP and vaginal microbicides, the development of behaviourally congruent products can play a primary role in uptake and adherence [94, 129, 130]. Overall, the studies described demonstrate that improving comprehensive HIV prevention packages with innovative tools means integrating sexual and reproductive health services, multi-purpose prevention products, and awareness of structural determinants experienced by sex workers that affect engagement in care.

\section{Research Gaps}

Studies on the global HIV burden on sex workers and its determinants over the last decade have built a substantial body of evidence demonstrating the unmet health needs of sex workers. Much of these data have focused on cisgender women sex workers, with substantive gaps in data among transgender sex workers, as well cisgender men sex workers disaggregated from studies of men who have sex with men. Most assessments and interventions have focused on the horizontal transmission of HIV among sex workers' sexual networks and its impact on overall population prevalence. Very few have taken into account interrelated issues faced by sex workers as parents, including their reproductive health outcomes, and the healthcare access and health outcomes of children of sex workers [131]. More research on these topics is needed. Additionally, younger sex workers are also vulnerable to experiencing many of the same determinants and burdens of HIV/STIs as sex workers overall, but are largely understudied. 
Studies have also discussed clients of sex workers as part of sexual transmission networks $[34,35]$, but there remains a dearth of data, particularly in sub-Saharan Africa, on the HIV/STI burden and determinants among sex work clients. Considering the role of clients in safe sex negotiations and experiences of violence, there is a need for more research, and particularly for the development of interventions tailored to reduce HIV/STI risks, violence, and onward transmission among clients [134-136].

There remains a need to better integrate HIV health services into more general health services for sex workers, including treatment and prevention services around obesity and diabetes, tuberculosis, other STIs, and sexual and reproductive health [126, 137, 138]. Key HIV comorbidities including tuberculosis, drug use, and chronic diseases require this approach, and research indicates that such integrated approaches may be most effective in reducing stigma and supporting the diverse array of health-related needs faced by sex workers.

Stigma, migration, criminalisation, violence, and associated policing practices remain major interrelated determinants of $\mathrm{HIV}$, as well as barriers to engagement in the HIV prevention and care continuums among sex workers. Additional action must be taken through multilevel interventions that address structural determinants. While there have been interventions driven by community empowerment, further community-driven research on implementation strategies remains needed to improve, expand, and sustain programmes shown to have significant positive effects on health outcomes.

\section{Conclusion}

The global response to the HIV pandemic has come with many achievements. However, over the last decade, the global response has also increased inequities in the burden of HIV by largely limited investment in HIV prevention and treatment services specifically dedicated for sex workers of all genders and identities. In particular, evidence-based and rights-affirming programme and policy responses to the HIV prevention and treatment needs of sex workers remain limited. Though there has been more research detailing social and structural determinants of HIV among sex workers, there is a need for dedicated quantitative and qualitative studies disentangling the complex relationships between these factors, and translation of these findings into multilevel interventions for sex workers to improve HIV outcomes that move beyond the individual level alone.

Existing community mobilisation approaches to improve sex worker health and well-being are encouraging, and major multilateral donors can play a primary role in supporting civil society organisations in adapting and scaling up evidence-based, rights-affirming programming. However, criminalisation has reduced the ability of sex workers to consistently engage in health services and continues to limit the reach of sex work-specific programming. Policymakers must step up and respond to international and local community voices speaking of the harmful effects of 
criminalisation on sex workers and turn to a focus on their health and human rights. In the coming decades, the HIV burden among sex workers will continue to be tied to the larger HIV pandemic, and addressing the unmet needs of sex workers remains essential to the HIV pandemic response.

\section{References}

1. Shannon K, Crago AL, Baral SD, Bekker LG, Kerrigan D, Decker MR, et al. The global response and unmet actions for HIV and sex workers. Lancet (London, England). 2018;392(10148):698-710.

2. Coetzee J, Jewkes R, Gray GE. Cross-sectional study of female sex workers in Soweto, South Africa: factors associated with HIV infection. PLoS One. 2017;12(10):e0184775.

3. Napierala S, Chabata ST, Fearon E, Davey C, Hargreaves J, Busza J, et al. Engagement in HIV care among Young female sex Workers in Zimbabwe. J Acquir Immune Defic Syndr. 2018;79(3):358-66.

4. Vu L, Misra K. High burden of HIV, syphilis and HSV-2 and factors associated with HIV infection among female sex Workers in Tanzania: implications for early treatment of HIV and pre-exposure prophylaxis (PrEP). AIDS Behav. 2018;22(4):1113-21.

5. Doshi RH, Sande E, Ogwal M, Kiyingi H, McIntyre A, Kusiima J, et al. Progress toward UNAIDS 90-90-90 targets: a respondent-driven survey among female sex workers in Kampala. Uganda PloS one. 2018;13(9):e0201352.

6. Teclessou JN, Akakpo S, Gbetoglo D, Koumagnanou G, Singo A, Pitche P. HIV prevalence and behavioral studies among female sex workers in Togo in 2015. Bulletin de la Societe de pathologie exotique (1990). 2017;110(4):270-5.

7. Szwarcwald CL, Damacena GN, de Souza-Junior PRB, Guimaraes MDC, de Almeida WDS, de Souza Ferreira AP, et al. Factors associated with HIV infection among female sex workers in Brazil. Medicine. 2018;97(1S Suppl 1):S54-s61.

8. Szwarcwald CL, de Almeida WDS, Damacena GN, de Souza-Junior PRB, Ferreira-Junior ODC, Guimaraes MDC. Changes in attitudes, risky practices, and HIV and syphilis prevalence among female sex workers in Brazil from 2009 to 2016. Medicine. 2018;97(1S Suppl 1):S46-s53.

9. The Joint United Nations HIV and AIDS Programme. The gap report. Geneva: UNAIDS; 2014.

10. The Joint United Nations HIV and AIDS Programme. Miles to go: global AIDS update 2018. Geneva: The Joint United Nations HIV and AIDS Programme; 2018.

11. Nuttbrock L. Transgender sex work and society: Columbia University Press; 2018.

12. Poteat T, Scheim A, Xavier J, Reisner S, Baral S. Global epidemiology of HIV infection and related syndemics affecting transgender people. J Acquir Immune Defic Syndr. 2016;72(Suppl 3):S210-9.

13. Reisner SL, Poteat T, Keatley J, Cabral M, Mothopeng T, Dunham E, et al. Global health burden and needs of transgender populations: a review. Lancet (London, England). 2016;388(10042):412-36.

14. Scheim AWL, Marshall Z, Jeffries D, Baral S. The prevalence of HIV among transwomen sex workers: a review of current literature. In: Nuttbrock L, editor. Transgender sex work and society, vol. 1. New York: Harrington Park Press, LLC; 2018. p. 118.

15. Costa AB, Fontanari AMV, Jacinto MM, da Silva DC, Lorencetti EK, da Rosa Filho HT, et al. Population-based HIV prevalence and associated factors in male-to-female transsexuals from Southern Brazil. Arch Sex Behav. 2015;44(2):521-4. 
16. Baral SD, Friedman MR, Geibel S, Rebe K, Bozhinov B, Diouf D, et al. Male sex workers: practices, contexts, and vulnerabilities for HIV acquisition and transmission. Lancet (London, England). 2015;385(9964):260-73.

17. Dong W, Zhou C, Jia MH, Zhou YJ, Chen X, Kang J, et al. HIV and syphilis infection and related medical treatment status of low-fee female sex workers in three provinces of China, 2012-2015. Zhonghua yu fang yi xue za zhi [Chinese journal of preventive medicine]. 2018;52(12):1239-42.

18. Lai J, Qin C, Nehl EJ, Jiang J, Huang Y, Liang B, et al. HIV prevalence among female sex workers in Guigang City, Guangxi, China: an 8-year consecutive cross-sectional study. BMC Public Health. 2018;18(1):450.

19. Zhu J, Yuan R, Hu D, Zhu Z, Wang N, Wang B. HIV prevalence and correlated factors of female sex workers and male clients in a border region of Yunnan Province, China. Int J STD AIDS. 2018;29(5):424-34.

20. Seekaew P, Pengnonyang S, Jantarapakde J, Sungsing T, Rodbumrung P, Trachunthong D, et al. Characteristics and HIV epidemiologic profiles of men who have sex with men and transgender women in key population-led test and treat cohorts in Thailand. PLoS One. 2018;13(8)

21. Goldsamt LA, Clatts MC, Giang LM, Le BQ, Colby DJ, Yu G. HIV and other STIs in male sex workers: findings from a sexual health promotion intervention in Vietnam. Int J STD AIDS. 2018;29(6):540-6.

22. Dumchev K, Sazonova Y, Salyuk T, Varetska O. Trends in HIV prevalence among people injecting drugs, men having sex with men, and female sex workers in Ukraine. Int J STD AIDS. 2018;29(13):1337-44.

23. Kouyoumjian SP, El Rhilani H, Latifi A, El Kettani A, Chemaitelly H, Alami K, et al. Mapping of new HIV infections in Morocco and impact of select interventions. Int J Infect Dis. 2018;68:4-12.

24. Becker ML, Bhattacharjee P, Blanchard JF, Cheuk E, Isac S, Musyoki HK, et al. Vulnerabilities at first sex and their association with lifetime gender-based violence and HIV prevalence among adolescent girls and young women engaged in sex work, transactional sex, and casual sex in Kenya. J Acquir Immune Defic Syndr. 2018;79(3):296-304.

25. Awofala AA, Ogundele OE. HIV epidemiology in Nigeria. Saudi journal of biological sciences. 2018;25(4):697-703.

26. Herce ME, Miller WM, Bula A, Edwards JK, Sapalalo P, Lancaster KE, et al. Achieving the first 90 for key populations in sub-Saharan Africa through venue-based outreach: challenges and opportunities for HIV prevention based on PLACE study findings from Malawi and Angola. J Int AIDS Soc. 2018;21:e25132.

27. Diabaté S, Chamberland A, Geraldo N, Tremblay C, Gonorrhea AM. Chlamydia and HIV incidence among female sex workers in Cotonou, Benin: a longitudinal study. PLoS One. 2018;13(5)

28. da Costa Ferreira-Júnior O, MDC G, Damacena GN, de Almeida WS, de Souza-Júnior PRB, Szwarcwald CL. Prevalence estimates of HIV, syphilis, hepatitis B and C among female sex workers (FSW) in Brazil, 2016. Medicine. 2018;97(1 Suppl)

29. Degtyar A, George PE, Mallma P, Diaz DA, Cárcamo C, García PJ, et al. Sexual risk, behavior, and HIV testing and status among male and transgender women sex workers and their clients in Lima, Peru. Int J Sex Health. 2018;30(1):81-91.

30. Fernàndez-López L, Reyes-Urueña J, Agustí C, Kustec T, Serdt M, Klavs I, et al. The COBATEST network: monitoring and evaluation of HIV community-based practices in Europe, 2014-2016. HIV Med. 2018;19:21-6.

31. Gama A, Martins MRO, Mendão L, Barros H, Dias S. HIV infection, risk factors and health services use among male-to-female transgender sex workers: a cross-sectional study in Portugal. AIDS Care. 2018;30(1):1-8.

32. Risher K, Mayer KH, Beyrer C. HIV treatment cascade in MSM, people who inject drugs, and sex workers. Curr Opin HIV AIDS. 2015;10(6):420-9. 
33. Hakim AJ, MacDonald V, Hladik W, Zhao J, Burnett J, Sabin K, et al. Gaps and opportunities: measuring the key population cascade through surveys and services to guide the HIV response. J Int AIDS Soc. 2018;21(Suppl 5):e25119.

34. Mountain E, Mishra S, Vickerman P, Pickles M, Gilks C, Boily MC. Antiretroviral therapy uptake, attrition, adherence and outcomes among HIV-infected female sex workers: a systematic review and meta-analysis. PLoS One. 2014;9(9):e105645.

35. Braunstein SL, Umulisa MM, Veldhuijzen NJ, Kestelyn E, Ingabire CM, Nyinawabega J, et al. HIV diagnosis, linkage to HIV care, and HIV risk behaviors among newly diagnosed HIV-positive female sex workers in Kigali, Rwanda. J Acquir Immune Defic Syndr. 2011;57(4):e70-6.

36. Schwartz S, Lambert A, Phaswana-Mafuya N, Kose Z, McIngana M, Holland C, et al. Engagement in the HIV care cascade and barriers to antiretroviral therapy uptake among female sex workers in Port Elizabeth, South Africa: findings from a respondent-driven sampling study. Sex Transm Infect. 2017;93(4):290-6.

37. Schwartz SR, Papworth E, Ky-Zerbo O, Anato S, Grosso A, Ouedraogo HG, et al. Safer conception needs for HIV prevention among female sex workers in Burkina Faso and Togo. Infect Dis Obstet Gynecol. 2014;2014:296245.

38. Lafort Y, Greener R, Roy A, Greener L, Ombidi W, Lessitala F, et al. HIV prevention and care-seeking behaviour among female sex workers in four cities in India, Kenya. Mozambique and South Africa Tropical medicine \& international health : TM \& IH. 2016;21(10):1293-303.

39. Lancaster KE, Lungu T, Mmodzi P, Hosseinipour MC, Chadwick K, Powers KA, et al. The association between substance use and sub-optimal HIV treatment engagement among HIVinfected female sex workers in Lilongwe, Malawi. AIDS Care. 2017;29(2):197-203.

40. Zulliger R, Barrington C, Donastorg Y, Perez M, Kerrigan D. High drop-off along the HIV care continuum and ART interruption among female sex workers in the Dominican Republic. J Acquir Immune Defic Syndr. 2015;69(2):216-22.

41. Januraga PP, Reekie J, Mulyani T, Lestari BW, Iskandar S, Wisaksana R, et al. The cascade of HIV care among key populations in Indonesia: a prospective cohort study. The lancet HIV. 2018;5(10):e560-e8.

42. Muth S, Len A, Evans JL, Phou M, Chhit S, Neak Y, et al. HIV treatment cascade among female entertainment and sex workers in Cambodia: impact of amphetamine use and an HIV prevention program. Addict Sci Clin Pract. 2017;12(1):20.

43. Goldenberg SM, Muzaaya G, Akello M, Braschel M, Birungi J, Shannon K. High burden of previously undiagnosed HIV infections and gaps in HIV care cascade for conflict-affected female sex workers in northern Uganda. Int J STD AIDS. 2019;30(3):275-83.

44. Hakim AJ, Johnston LG, Dittrich S, Prybylski D, Burnett J, Kim E. Defining and surveying key populations at risk of HIV infection: towards a unified approach to eligibility criteria for respondent-driven sampling HIV biobehavioral surveys. Int J STD AIDS. 2018;29(9):895-903.

45. Lancaster KE, Cernigliaro D, Zulliger R, Fleming PF. HIV care and treatment experiences among female sex workers living with HIV in sub-Saharan Africa: a systematic review. African journal of AIDS research : AJAR. 2016;15(4):377-86.

46. Nyblade L, Reddy A, Mbote D, Kraemer J, Stockton M, Kemunto C, et al. The relationship between health worker stigma and uptake of HIV counseling and testing and utilization of non-HIV health services: the experience of male and female sex workers in Kenya. AIDS Care. 2017;29(11):1364-72.

47. Carrasco MA, Nguyen TQ, Barrington C, Perez M, Donastorg Y, Kerrigan D. HIV stigma mediates the association between social cohesion and consistent condom use among female sex workers living with HIV in the Dominican Republic. Arch Sex Behav. 2018;47(5):1529-39.

48. Hargreaves JR, Busza J, Mushati P, Fearon E, Cowan FM. Overlapping HIV and sex-work stigma among female sex workers recruited to 14 respondent-driven sampling surveys across Zimbabwe, 2013. AIDS Care. 2017;29(6):675-85. 
49. Miller WM, Miller WC, Barrington C, Weir SS, Chen SY, Emch ME, et al. Sex work, discrimination, drug use and violence: a pattern for HIV risk among transgender sex workers compared to MSM sex workers and other MSM in Guatemala. Glob Public Health. 2019:1-13.

50. Lyons CE, Ketende S, Diouf D, Drame FM, Liestman B, Coly K, et al. Potential impact of integrated stigma mitigation interventions in improving HIV/AIDS service delivery and uptake for key populations in Senegal. J Acquir Immune Defic Syndr. 2017;74(Suppl 1):S52-s9.

51. Tandon t A-CG, Grover A. Sex work and trafficking: can human rights lead us out of the impasse? ; 2014.

52. Platt L, Grenfell P, Meiksin R, Elmes J, Sherman SG, Sanders T, et al. Associations between sex work laws and sex workers' health: a systematic review and meta-analysis of quantitative and qualitative studies. PLoS Med. 2018;15(12):e1002680.

53. Amnesty International. Policy on state oblication to respect, uphold and fulfil the human rights of sex workers. May. 2016;26

54. Krusi A, Kerr T, Taylor C, Rhodes T, Shannon K. They won't change it back in their heads that we're trash': the intersection of sex work-related stigma and evolving policing strategies. Sociol Health Illn. 2016;38(7):1137-50.

55. Shannon K, Strathdee SA, Goldenberg SM, Duff P, Mwangi P, Rusakova M, et al. Global epidemiology of HIV among female sex workers: influence of structural determinants. Lancet (London, England). 2015;385(9962):55-71.

56. Reeves A, Steele S, Stuckler D, McKee M, Amato-Gauci A, Semenza JC. Gender violence, poverty and HIV infection risk among persons engaged in the sex industry: cross-national analysis of the political economy of sex markets in 30 European and Central Asian countries. HIV Med. 2017;18(10):748-55.

57. Lyons CE, Schwartz SR, Murray SM, Shannon K, Diouf D, Mothopeng T, et al. The role of sex work laws and stigmas in increasing HIV risks among sex workers. Nat Commun 2020;11(1):1-10.

58. Krusi A, Pacey K, Bird L, Taylor C, Chettiar J, Allan S, et al. Criminalisation of clients: reproducing vulnerabilities for violence and poor health among street-based sex workers in Canada-a qualitative study. BMJ Open. 2014;4(6):e005191.

59. Decker MR, Lyons C, Billong SC, Njindam IM, Grosso A, Nunez GT, et al. Gender-based violence against female sex workers in Cameroon: prevalence and associations with sexual HIV risk and access to health services and justice. Sex Transm Infect. 2016;92(8):599-604.

60. Roberts ST, Flaherty BP, Deya R, Masese L, Ngina J, McClelland RS, et al. Patterns of gender-based violence and associations with mental health and HIV risk behavior among female sex workers in Mombasa, Kenya: a latent class analysis. AIDS Behav. 2018;22(10):3273-86.

61. Wirtz AL, Schwartz S, Ketende S, Anato S, Nadedjo FD, Ouedraogo HG, et al. Sexual violence, condom negotiation, and condom use in the context of sex work: results from two West African countries. J Acquir Immune Defic Syndr. 2015;68(Suppl 2):S171-9.

62. Footer KHA, Silberzahn BE, Tormohlen KN, Sherman SG. Policing practices as a structural determinant for HIV among sex workers: a systematic review of empirical findings. J Int AIDS Soc. 2016;19:20883.

63. Abel GF, Lisa, Brunton C. The impact of prostitution reform act on health and safety practices of sex workers. Christchurch, New Zealand: University of Otago; 2007.

64. Harcourt C, O'Connor J, Egger S, Fairley CK, Wand H, Chen MY, et al. The decriminalization of prostitution is associated with better coverage of health promotion programs for sex workers. Aust N Z J Public Health. 2010;34(5):482-6.

65. Ito S, Lepine A, Treibich C. The effect of sex work regulation on health and well-being of sex workers: evidence from Senegal. Health Econ. 2018;27(11):1627-52.

66. Duff P, Birungi J, Dobrer S, Akello M, Muzaaya G, Shannon K. Social and structural factors increase inconsistent condom use by sex workers' one-time and regular clients in Northern Uganda. AIDS Care. 2018;30(6):751-9. 
67. Lasater ME, Grosso A, Ketende S, Lyons C, Pitche VP, Tchalla J, et al. Characterising the relationship between migration and stigma affecting healthcare engagement among female sex workers in Lome. Togo Global public health. 2019:1-14.

68. International Committee on the Rights of Sex Workers in Europe. Surveilled. Exploited. Deported. Rights Violations Against Migrant Sex Workers in Europe and Central Asia. November 2016:2016.

69. Platt L, Grenfell P, Fletcher A, Sorhaindo A, Jolley E, Rhodes T, et al. Systematic review examining differences in HIV, sexually transmitted infections and health-related harms between migrant and non-migrant female sex workers. Sex Transm Infect. 2013;89(4):311-9.

70. Goldenberg SM, Chettiar J, Nguyen P, Dobrer S, Montaner J, Shannon K. Complexities of short-term mobility for sex work and migration among sex workers: violence and sexual risks, barriers to care, and enhanced social and economic opportunities. J Urban Health. 2014;91(4):736-51.

71. Davey C, Dirawo J, Hargreaves JR, Cowan FM. Exploring the association between mobility and access to HIV services among female sex workers in Zimbabwe. AIDS Behav. 2020;24(3):746-61.

72. Global Network of Sex Work P. Sex work and the law: understanding legal frameworks and the struggle for sex work law reforms. 2014.

73. Wirtz AL, Peryshkina A, Mogilniy V, Beyrer C, Decker MR. Current and recent drug use intensifies sexual and structural HIV risk outcomes among female sex workers in the Russian Federation. Int J Drug Policy. 2015;26(8):755-63.

74. Dunne EM, Dyer TP, Khan MR, Cavanaugh CE, Melnikov A, Latimer WW. HIV prevalence and risk behaviors among African American women who trade sex for drugs versus economic resources. AIDS Behav. 2014;18(7):1288-92.

75. Le LV, Nguyen TA, Tran HV, Gupta N, Duong TC, Tran HT, et al. Correlates of HIV infection among female sex workers in Vietnam: injection drug use remains a key risk factor. Drug Alcohol Depend. 2015;150:46-53.

76. Bozinoff N, Luo L, Dong H, Krusi A, DeBeck K. Street-involved youth engaged in sex work at increased risk of syringe sharing. AIDS Care. 2019;31(1):69-76.

77. Nemoto T, Iwamoto M, Perngparn U, Areesantichai C, Kamitani E, Sakata M. HIV-related risk behaviors among kathoey (male-to-female transgender) sex workers in Bangkok, Thailand. AIDS Care. 2012;24(2):210-9.

78. Nuttbrock L. Sex work, high-risk sexual behavior, and incident HIV/STI among transwomen in New York City: a study of mediating factors. In: Nuttbrock L, editor. Transgender sex work and society. 1. New York: Harrington Park Press, LLC; 2018. p. 164-85.

79. Kerrigan D, Kennedy CE, Morgan-Thomas R, Reza-Paul S, Mwangi P, Win KT, et al. A community empowerment approach to the HIV response among sex workers: effectiveness, challenges, and considerations for implementation and scale-up. Lancet (London, England). 2015;385(9963):172-85.

80. World Health Organization. Implementing comprehensive HIV/STI programmes with sex workers: practical approaches from collaborative interventions. Geneva: World Health Organization.; 2013 October; 2013.

81. Beattie TS, Mohan HL, Bhattacharjee P, Chandrashekar S, Isac S, Wheeler T, et al. Community mobilization and empowerment of female sex workers in Karnataka State, South India: associations with HIV and sexually transmitted infection risk. Am J Public Health. 2014;104(8):1516-25.

82. Blanchard AK, Mohan HL, Shahmanesh M, Prakash R, Isac S, Ramesh BM, et al. Community mobilization, empowerment and HIV prevention among female sex workers in South India. BMC Public Health. 2013;13:234.

83. Ghose T, Swendeman D, George S, Chowdhury D. Mobilizing collective identity to reduce HIV risk among sex workers in Sonagachi, India: the boundaries, consciousness, negotiation framework. Soc Sci Med. 2008;67(2):311-20. 
84. Cornish F, Campbell C. The social conditions for successful peer education: a comparison of two HIV prevention programs run by sex workers in India and South Africa. Am J Community Psychol. 2009;44(1-2):123-35.

85. Alary M, Banandur P, Rajaram SP, Thamattoor UK, Mainkar MK, Paranjape R, et al. Increased HIV prevention program coverage and decline in HIV prevalence among female sex workers in South India. Sex Transm Dis. 2014;41(6):380-7.

86. Avahan India AI. Avahan common minimum program for HIV prevention in India. Bill \& Melinda Gates Foundation: New Delhi; 2010.

87. Kerrigan D, Barrington C, Donastorg Y, Perez M, Galai N. Abriendo Puertas: feasibility and effectiveness a multi-level intervention to improve HIV outcomes among female sex workers living with HIV in the Dominican Republic. AIDS Behav. 2016;20(9):1919-27.

88. Carrasco MA, Barrington C, Perez M, Donastorg Y, Kerrigan D. Social cohesion, condom use, and sexually transmitted infections among female sex workers living with HIV in the Dominican Republic. Int J STD AIDS. 2019;30(1):64-71.

89. Lippman SA, Chinaglia M, Donini AA, Diaz J, Reingold A, Kerrigan DL. Findings from Encontros: a multilevel STI/HIV intervention to increase condom use, reduce STI, and change the social environment among sex workers in Brazil. Sex Transm Dis. 2012;39(3):209-16.

90. Wirtz AL, Pretorius C, Beyrer C, Baral S, Decker MR, Sherman SG, et al. Epidemic impacts of a community empowerment intervention for HIV prevention among female sex workers in generalized and concentrated epidemics. PLoS One. 2014;9(2):e88047.

91. Bekker LG, Johnson L, Cowan F, Overs C, Besada D, Hillier S, et al. Combination HIV prevention for female sex workers: what is the evidence? Lancet (London, England). 2015;385(9962):72-87.

92. Eakle R, Gomez GB, Naicker N, Bothma R, Mbogua J, Cabrera Escobar MA, et al. HIV pre-exposure prophylaxis and early antiretroviral treatment among female sex workers in South Africa: results from a prospective observational demonstration project. PLoS Med. 2017;14(11):e1002444.

93. Restar AJ, Tocco JU, Mantell JE, Lafort Y, Gichangi P, Masvawure TB, et al. Perspectives on HIV pre- and post-exposure prophylaxes (PrEP and PEP) among female and male sex Workers in Mombasa, Kenya: implications for integrating biomedical prevention into sexual health services. AIDS education and prevention : official publication of the International Society for AIDS Education. 2017;29(2):141-53.

94. Peitzmeier SM, Tomko C, Wingo E, Sawyer A, Sherman SG, Glass N, et al. Acceptability of microbicidal vaginal rings and oral pre-exposure prophylaxis for HIV prevention among female sex workers in a high-prevalence US city. AIDS Care. 2017;29(11):1453-7.

95. Cowan FM, Delany-Moretlwe S, Sanders EJ, Mugo NR, Guedou FA, Alary M, et al. PrEP implementation research in Africa: what is new? J Int AIDS Soc. 2016;19(7(Suppl 6)):21101.

96. Giguere R, Frasca T, Dolezal C, Febo I, Cranston RD, Mayer K, et al. Acceptability of three novel HIV prevention methods among young male and transgender female sex Workers in Puerto Rico. AIDS Behav. 2016;20(10):2192-202.

97. Organization WH. Consolidated guidelines on HIV testing services; 5Cs: consent, confidentiality, counseling, correct results and connection. Geneva, Switzerland; 2015.

98. Ortblad K, Kibuuka Musoke D, Ngabirano T, Nakitende A, Magoola J, Kayiira P, et al. Direct provision versus facility collection of HIV self-tests among female sex workers in Uganda: a cluster-randomized controlled health systems trial. PLoS Med. 2017;14(11):e1002458.

99. Chanda MM, Ortblad KF, Mwale M, Chongo S, Kanchele C, Kamungoma N, et al. HIV selftesting among female sex workers in Zambia: a cluster randomized controlled trial. PLoS Med. 2017;14(11):e1002442.

100. Ortblad KF, Chanda MM, Musoke DK, Ngabirano T, Mwale M, Nakitende A, et al. Acceptability of HIV self-testing to support pre-exposure prophylaxis among female sex workers in Uganda and Zambia: results from two randomized controlled trials. BMC Infect Dis. 2018;18(1):503. 
101. George G, Chetty T, Strauss M, Inoti S, Kinyanjui S, Mwai E, et al. Costing analysis of an SMS-based intervention to promote HIV self-testing amongst truckers and sex workers in Kenya. PLoS One. 2018;13(7):e0197305.

102. Thomson KA, Baeten JM, Mugo NR, Bekker LG, Celum CL, Heffron R. Tenofovir-based oral preexposure prophylaxis prevents HIV infection among women. Curr Opin HIV AIDS. 2016;11(1):18-26.

103. Eakle R, Gomez G, Naicker N, Bothma R, Mbogua J. Escobar M.A.C, et al., editors. PrEP and early ART for female sex workers in South Africa: the TAPS project. Conference on retroviruses and opportunistic infections; 2018; Boston. Massachusetts.

104. McCormack S, Dunn DT, Desai M, Dolling DI, Gafos M, Gilson R, et al. Pre-exposure prophylaxis to prevent the acquisition of HIV-1 infection (PROUD): effectiveness results from the pilot phase of a pragmatic open-label randomised trial. Lancet (London, England). 2016;387(10013):53-60.

105. Grinsztejn B, Hoagland B, Moreira RI, Kallas EG, Madruga JV, Goulart S, et al. Retention, engagement, and adherence to pre-exposure prophylaxis for men who have sex with men and transgender women in PrEP Brasil: 48 week results of a demonstration study. The lancet HIV. 2018;5(3):e136-e45.

106. WHO. Guideline on when to start antiretroviral therapy and on pre-exposure prophylaxis for HIV: World Health Organization; 2015.

107. Grant H, Mukandavire Z, Eakle R, Prudden H, Gomez Gabriela B, Rees H, et al. When are declines in condom use while using PrEP a concern? Modelling insights from a Hillbrow, South Africa case study. J Int AIDS Soc. 2017;20(1):21744.

108. Mboup A, Béhanzin L, Guédou FA, Geraldo N, Goma-Matsétsé E, Giguère K, et al. Early antiretroviral therapy and daily pre-exposure prophylaxis for HIV prevention among female sex workers in Cotonou, Benin: a prospective observational demonstration study. J Int AIDS Soc. 2018;21(11):e25208.

109. Fonner VA, Dalglish SL, Kennedy CE, Baggaley R, O'Reilly KR, Koechlin FM, et al. Effectiveness and safety of oral HIV preexposure prophylaxis for all populations. AIDS (London, England). 2016;30(12):1973-83.

110. Daniel Were, E. I, editors. PrEP scale up in Kenya: bridge to scale project. International AIDS Society Conference on HIV science; 2017. July 25, 2017; Paris, France.

111. Cowan FM, Davey CB, Fearon E, Mushati P, Dirawo J, Cambiano V, et al. The HIV care Cascade among female sex Workers in Zimbabwe: results of a population-based survey from the sisters antiretroviral therapy Programme for prevention of HIV, an integrated response (SAPPH-IRe) trial. J Acquir Immune Defic Syndr. 2017;74(4):375-82.

112. Gill KPT, Dietrich J, Gray G, Bennie T, Kayamba F, Myer L, Johnson L, Slack C, Strode A, Spiegel H, Elharrar V, Hosek S, Rooney J, Bekker L. A demonstration open label study to assess the acceptability, safety and use of Truvada pre-exposure prophylaxis in healthy, HIVUninfected adolescents, 15-19 years of age. 9th International AIDS Conference. 2017; Paris, France

113. Goparaju L, Praschan NC, Warren-Jeanpiere L, Experton LS, Young MA, Kassaye S. Stigma, partners, providers and costs: potential barriers to PrEP uptake among US women. Journal of AIDS \& clinical research. 2017;8(9)

114. Mack N, Odhiambo J, Wong CM, Agot K. Barriers and facilitators to pre-exposure prophylaxis (PrEP) eligibility screening and ongoing HIV testing among target populations in Bondo and Rarieda. Kenya: results of a consultation with community stakeholders BMC health services research. 2014;14:231.

115. Goparaju L, Experton LS, Praschan NC, Warren-Jeanpiere L, Young MA, Kassaye S. Women want pre-exposure prophylaxis but are advised against it by their HIV-positive counterparts. Journal of AIDS \& clinical research. 2015;6(11):1-10.

116. Eakle R, Bourne A, Jarrett C, Stadler J, Larson H. Motivations and barriers to uptake and use of female-initiated, biomedical HIV prevention products in sub-Saharan Africa: an adapted meta-ethnography. BMC Public Health. 2017;17(1):968. 
117. Hartmann M, McConnell M, Bekker LG, Celum C, Bennie T, Zuma J, et al. Motivated reasoning and HIV risk? Views on relationships, trust, and risk from young women in Cape Town, South Africa, and implications for Oral PrEP. AIDS Behav. 2018;22(11):3468-79.

118. van der Straten A, Stadler J, Montgomery E, Hartmann M, Magazi B, Mathebula F, et al. Women's experiences with oral and vaginal pre-exposure prophylaxis: the VOICE-C qualitative study in Johannesburg, South Africa. PLoS One. 2014;9(2):e89118.

119. Quaife M, Vickerman P, Manian S, Eakle R, Cabrera-Escobar MA, Delany-Moretlwe S, et al. The effect of HIV prevention products on incentives to supply condomless commercial sex among female sex workers in South Africa. Health Econ. 2018;27(10):1550-66.

120. Deutsch MB, Glidden DV, Sevelius J, Keatley J, McMahan V, Guanira J, et al. HIV pre-exposure prophylaxis in transgender women: a subgroup analysis of the iPrEx trial. The lancet HIV. 2015;2(12):e512-e9.

121. Kambutse I, Igiraneza G, Ogbuagu O. Perceptions of HIV transmission and pre-exposure prophylaxis among health care workers and community members in Rwanda. PLoS One. 2018;13(11):e0207650.

122. Scorgie F, Chersich MF, Ntaganira I, Gerbase A, Lule F, Lo YR. Socio-demographic characteristics and behavioral risk factors of female sex workers in sub-saharan Africa: a systematic review. AIDS Behav. 2012;16(4):920-33.

123. Beckham SW, Shembilu CR, Brahmbhatt H, Winch PJ, Beyrer C, Kerrigan DL. Female sex workers' experiences with intended pregnancy and antenatal care services in southern Tanzania. Stud Fam Plan. 2015;46(1):55-71.

124. Papworth E, Schwartz S, Ky-Zerbo O, Leistman B, Ouedraogo G, Samadoulougou C, et al. Mothers who sell sex: a potential paradigm for integrated HIV, sexual, and reproductive health interventions among women at high risk of HIV in Burkina Faso. J Acquir Immune Defic Syndr. 2015;68(Suppl 2):S154-61.

125. Duff P, Evans JL, Stein ES, Page K, Maher L. High pregnancy incidence and low contraceptive use among a prospective cohort of female entertainment and sex workers in Phnom Penh, Cambodia. BMC Pregnancy Childbirth. 2018;18(1):128.

126. Lafort Y, Greener L, Lessitala F, Chabeda S, Greener R, Beksinska M, et al. Effect of a 'diagonal' intervention on uptake of HIV and reproductive health services by female sex workers in three sub-Saharan African cities. Tropical medicine \& international health : TM \& IH. 2018;23(7):774-84.

127. Ferguson A, Shannon K, Butler J, Goldenberg SM. A comprehensive review of HIV/STI prevention and sexual and reproductive health services among sex Workers in Conflict-Affected Settings: call for an evidence- and rights-based approach in the humanitarian response. Confl Heal. 2017;11:25.

128. Rinaldi G, Kiadaliri AA, Haghparast-Bidgoli H. Cost effectiveness of HIV and sexual reproductive health interventions targeting sex workers: a systematic review. Cost effectiveness and resource allocation : C/E. 2018;16:63.

129. Pines HA, Strathdee SA, Hendrix CW, Bristow CC, Harvey-Vera A, Magis-Rodriguez C, et al. Oral and vaginal HIV pre-exposure prophylaxis product attribute preferences among female sex workers in the Mexico-US border region. Int J STD AIDS. 2019;30(1):45-55.

130. Pines HA, Semple SJ, Strathdee SA, Hendrix CW, Harvey-Vera A, Gorbach PM, et al. Vaginal washing and lubrication among female sex workers in the Mexico-US border region: implications for the development of vaginal PrEP for HIV prevention. BMC Public Health. 2018;18(1):1009.

131. Schwartz SR, Papworth E, Ky-Zerbo O, Sithole B, Anato S, Grosso A, et al. Reproductive health needs of female sex workers and opportunities for enhanced prevention of motherto-child transmission efforts in sub-Saharan Africa. J Fam Plann Reprod Health Care. 2017;43(1):50-9.

132. Papworth E, Ceesay N, An L, Thiam-Niangoin M, Ky-Zerbo O, Holland C, et al. Epidemiology of HIV among female sex workers, their clients, men who have sex with men and people who inject drugs in west and Central Africa. J Int AIDS Soc. 2013;16(Suppl 3):18751. 
133. Subramanian T, Gupte MD, Paranjape RS, Brahmam GN, Ramakrishnan L, Adhikary R, et al. HIV, sexually transmitted infections and sexual behaviour of male clients of female sex workers in Andhra Pradesh, Tamil Nadu and Maharashtra, India: results of a cross-sectional survey. AIDS (London, England). 2008;22(Suppl 5):S69-79.

134. Kohli A, Kerrigan D, Brahmbhatt H, Likindikoki S, Beckham J, Mwampashi A, et al. Social and structural factors related to HIV risk among truck drivers passing through the Iringa region of Tanzania. AIDS Care. 2017;29(8):957-60.

135. Matovu JK, Ssebadduka NB. Knowledge, attitudes \& barriers to condom use among female sex workers and truck drivers in Uganda: a mixed-methods study. Afr Health Sci. 2013;13(4):1027-33.

136. Pitpitan EV, Chavarin CV, Semple SJ, Magis-Rodriguez C, Strathdee SA, Patterson TL. Hombre Seguro (Safe Men): a sexual risk reduction intervention for male clients of female sex workers. BMC Public Health. 2014;14:475.

137. Steiner RJ, Aquino G, Fenton KA. Enhancing HIV/AIDS, viral hepatitis, sexually transmitted disease, and tuberculosis prevention in the United States through program collaboration and service integration: the case for broader implementation. Sex Transm Dis. 2013;40(8):663-8.

138. Haldane V, Legido-Quigley H, Chuah FLH, Sigfrid L, Murphy G, Ong SE, et al. Integrating cardiovascular diseases, hypertension, and diabetes with HIV services: a systematic review. AIDS Care. 2018;30(1):103-15.

Open Access This chapter is licensed under the terms of the Creative Commons Attribution 4.0 International License (http://creativecommons.org/licenses/by/4.0/), which permits use, sharing, adaptation, distribution and reproduction in any medium or format, as long as you give appropriate credit to the original author(s) and the source, provide a link to the Creative Commons license and indicate if changes were made.

The images or other third party material in this chapter are included in the chapter's Creative Commons license, unless indicated otherwise in a credit line to the material. If material is not included in the chapter's Creative Commons license and your intended use is not permitted by statutory regulation or exceeds the permitted use, you will need to obtain permission directly from the copyright holder.

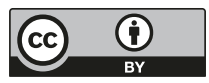

